\title{
Fast Analysis of Water Samples for Trace Amount of Crystal Violet Dye Based on Solid Phase Extraction Using Nanoporous SBA-3 prior to Determination by Fiber Optic-Linear Array Detection Spectrophotometry
}

\author{
Azam Azarkohan, Farzaneh Shemirani, and Mahrouz Alvand \\ Department of Analytical Chemistry, Faculty of Chemistry, University College of Science, University of Tehran, \\ P.O. Box 14155-6455, Tehran, Iran \\ Correspondence should be addressed to Farzaneh Shemirani; shemiran@khayam.ut.ac.ir
}

Received 17 June 2013; Revised 28 October 2013; Accepted 28 October 2013

Academic Editor: Jean-Luc Blin

Copyright (c) 2013 Azam Azarkohan et al. This is an open access article distributed under the Creative Commons Attribution License, which permits unrestricted use, distribution, and reproduction in any medium, provided the original work is properly cited.

A solid phase preconcentration procedure using SBA-3 nanosorbent for the fast separation and preconcentration of crystal violet $(\mathrm{CV})$ in water samples by fiber optic-linear array detection spectrophotometry (FO-LADS) is presented. Experimental parameters including $\mathrm{pH}$, sample volume, amount of sorbent, type, volume, and concentration of eluent that affect the recovery of crystal violet have been optimized. Under optimized experimental conditions, analytical parameters including limit of detection, linear working range, and relative standard deviation have also been determined. A preconcentration factor of 200 was achieved in this method. In the initial solution, the detection limit for $\mathrm{CV}$ was found as $1.3 \mu \mathrm{g} \mathrm{L} \mathrm{L}^{-1}$. Under optimal conditions maximum adsorption capacity was obtained as $344.83 \mathrm{mg} \mathrm{g}^{-1}$. Also, the relative standard deviation was less than $\pm 1.3 \%(n=5)$. The presented procedure was applied to the determination of crystal violet in water samples (fish, fish farming water, and river water) with good results.

\section{Introduction}

Crystal violet, a synthetic basic cationic dye, in Figure 1 imparts violet color in aqueous solution. The cationic dyes are more toxic than the anionic dyes [1], as these can easily interact with negatively charged cell membrane surfaces and can enter into cells and concentrate in cytoplasm [2]. Crystal violet is used in variety of ways: as a biological stain, dermatological agent, veterinary medicine, additive to poultry feed to inhibit propagation of mold, intestinal parasites and fungus, textile dying and paper printing, and so forth [3]. However, crystal violet (CV) is also carcinogenic and has been classified as a recalcitrant molecule since it is poorly metabolized by microbes, is nonbiodegradable, and can persist in a variety of environments [4].

In response to concerns regarding the health risks associated with the use of crystal violet, even at trace levels, an increasing number of methods have been developed in recent years for its preconcentration and determination such as cloud point extraction (CPE), solid phase extraction (SPE), and rotating disk sportive extraction (RDSE) [5-7].

Among these preconcentration techniques, solid phase extraction is preferred by lots of researchers due to its advantages including simple and fast extractor system. It has a relatively high concentration factor and the ability of treating large volume samples free from contamination. The choice of the sorbent is a key point in SPE [8], because it determines the analytical sensitivity, affinity, capacity, and precision [9].

In 1992, the discovery of the ordered mesoporous material MCM-41 opened up a new research field in mesoporous materials that were highly desirable for application in processes that involve large molecules [10]. Recent works have shown that mesoporous materials [11-13] can have large adsorption capacity, good selectivity, and improved powder recoverability for the removal of toxic compounds from aqueous solutions.

In 1996, Huo et al. [14] synthesized a new type of mesoporous material called SBA, with uniform hexagonal 


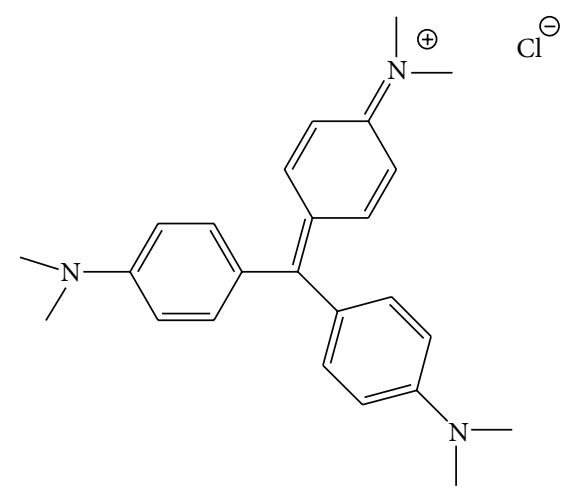

FIGURE 1: Structural formula of CV.

structure. SBA-3-type mesoporous molecular sieves were synthesized using a low molecular weight alkyl quaternary ammonium template room temperature and under acidic condition. A well-established fact is that SBA-3 has a negative charge density due to the presence of $\mathrm{Si}-\mathrm{O}$ and $\mathrm{Si}-\mathrm{OH}$ groups, which makes this sorbent suitable for adsorption of cationic crystal violet dye through electrostatic interactions (Figure 2).

In this work, highly ordered silica mesoporous molecular sieves (SBA-3) were synthesized for fast and efficient extraction of crystal violet dye from water samples. The structural order and textural properties of the synthesized materials were studied by XRD, SEM, and Nitrogen adsorptiondesorption analysis.

The optimum conditions for sorption and enrichment of crystal violet were studied. In addition, the possible use of the developed method for analyzing CV in water sample solutions was explored.

\section{Materials and Methods}

2.1. Instrumentation. The determination of crystal violet was carried out using a UV-Vis light source, optical fibers, and spectrograph (model 2048) that were purchased from Avantes (Eerbeek, The Netherlands). A quartz microcell from Starna Scientific (Essex, UK, Cat. No.16.40F-Q10/Z15) was used. The pH-meter Model 692 from Metrohm (http://www.metrohm.com/, Herisau, Switzerland) equipped with a glass combination electrode was used for the $\mathrm{pH}$ measurements. The XRD pattern was recorded on a Philips 1830 diffractometer using $\mathrm{Cu} \mathrm{K} \alpha$ radiation. The diffractograms were recorded in the $2 \theta$ range of $(1-10)^{\circ}$ with a $2 \theta$ step size of $0.018^{\circ}$ and a step time of $1 \mathrm{~s}$. Adsorption desorption isotherms of the synthesized samples were measured at $77 \mathrm{~K}$ on Micromeritics model ASAP 2010 sorptometer to determine an average pore diameter. Pore-size distributions were calculated by the Barrett-Joyner-Halenda (BJH) method, while surface area of the samples was measured by BrunauerEmmett-Teller (BET) method. Scanning electron microscope (SEM) images of these solids were obtained with a Philips XL30 instrument after gold metallization.

2.2. Reagents and Solutions. The reactants used in this study were tetraethyl orthosilicate (TEOS) as a silica deionized water for synthesis of mesoporous silica (SBA-3) and crystal violet dye (C.I. 42555, $\lambda_{\max }=584 \mathrm{~nm}$, molecular formula $\mathrm{C}_{25} \mathrm{H}_{30} \mathrm{~N}_{3} \mathrm{Cl}$ ). Dye solution was prepared by dissolving an appropriate amount of dye in double distilled water. The dye solution $\mathrm{pH}$ was adjusted using $0.1 \mathrm{~N} \mathrm{HCl}$ or $0.1 \mathrm{~N} \mathrm{NaOH}$. All chemicals used were of analytical reagent grade and all aqueous solutions were prepared using ultrapure water (E. Merck (Germany)) source, cetyltrimethylammonium bromide $(\mathrm{CTAB})$ as a surfactant, and hydrochloric acid $(\mathrm{HCl})$.

2.3. Synthesis of Mesoporous Silica (SBA-3). SBA-3 was prepared according to the synthesis procedure described by Huo et al. [14]. The SBA-3 molecular sieve was prepared as follows. Cetyltrimethylammonium bromide (CTAB) and tetraethyl orthosilicate (TEOS) were used as surfactant and silica source, respectively. An aqueous solution of $\mathrm{HCl}$ (Baker, $37 \%$ ) was used to adjust the $\mathrm{pH}$ value of the reaction mixture. One gram of CTAB and $15 \mathrm{~mL}$ of $\mathrm{HCl}(37 \%)$ were dissolved in $47 \mathrm{~mL}$ of deionized water. TEOS $(4.45 \mathrm{~mL})$ was then added dropwise to the acidic CTAB solution, while it was stirred at $400 \mathrm{rpm}$ and $30^{\circ} \mathrm{C}$. After $1 \mathrm{~h}$, the resultant white precipitate (as-synthesized SBA-3) was filtered without washing and dried at $100^{\circ} \mathrm{C}$ overnight. The as-synthesized SBA-3 powder was calcined at $550^{\circ} \mathrm{C}$ in air for $5 \mathrm{~h}$ prior to characterization. The heating rate to $550^{\circ} \mathrm{C}$ was $1^{\circ} \mathrm{C} / \mathrm{min}$.

2.4. Procedure. Batch static preconcentration studies were carried out by taking $25 \mathrm{~mL}$ of sample solution containing $1.25 \mu \mathrm{g}$ of crystal violet dye and adjusting the $\mathrm{pH}$ to around 9. $15 \mathrm{mg}$ of SBA-3 was added to the above solution and stirred for $2 \mathrm{~min}$. After filtration and removal the enriched dye was eluted with $1 \mathrm{~mL}$ of glacial acetic acid and subjected to a fiber optic spectrograph (Avantes; model: 2048) using a 50$\mu \mathrm{L}$ quartz cylindrical microcell at $590.0 \mathrm{~nm}$. Control or blank experiments containing no dye molecules were also done in a similar manner.

2.5. Equilibrium Isotherms. The amount of the adsorbed CV on the SBA-3 was calculated based on the following equation:

$$
q_{e}=\left(C_{0}-C_{e}\right) \frac{V}{W}
$$

where $q_{e}$ is the amount of the adsorbed CV on the SBA-3 $\left(\mathrm{mg} \mathrm{g}^{-1}\right), C_{0}$ is the initial concentration of the $\mathrm{CV}\left(\mathrm{mg} \mathrm{L}^{-1}\right)$, $C_{e}$ is the equilibrium concentration of the $\mathrm{CV}$ in the solution $\left(\mathrm{mg} \mathrm{L}^{-1}\right), V$ is the volume of the $\mathrm{CV}$ solution $(\mathrm{L})$, and $W$ is the weight of the dry CV added. For evaluating the equilibrium adsorption, several isotherm models which are essential for designing and optimizing the adsorption processes have been developed such as Langmuir [15]. The linearized form of the Langmuir isotherm, assuming monolayer adsorption on a homogeneous adsorbent surface, is expressed as

$$
\frac{C_{e}}{q_{e}}=\frac{1}{b q_{\max }}+\frac{C_{e}}{q_{\max }},
$$

where $q_{\max }\left(\mathrm{mgg}^{-1}\right)$ is the surface concentration at monolayer coverage and illustrates the maximum value of $q_{e}$ 


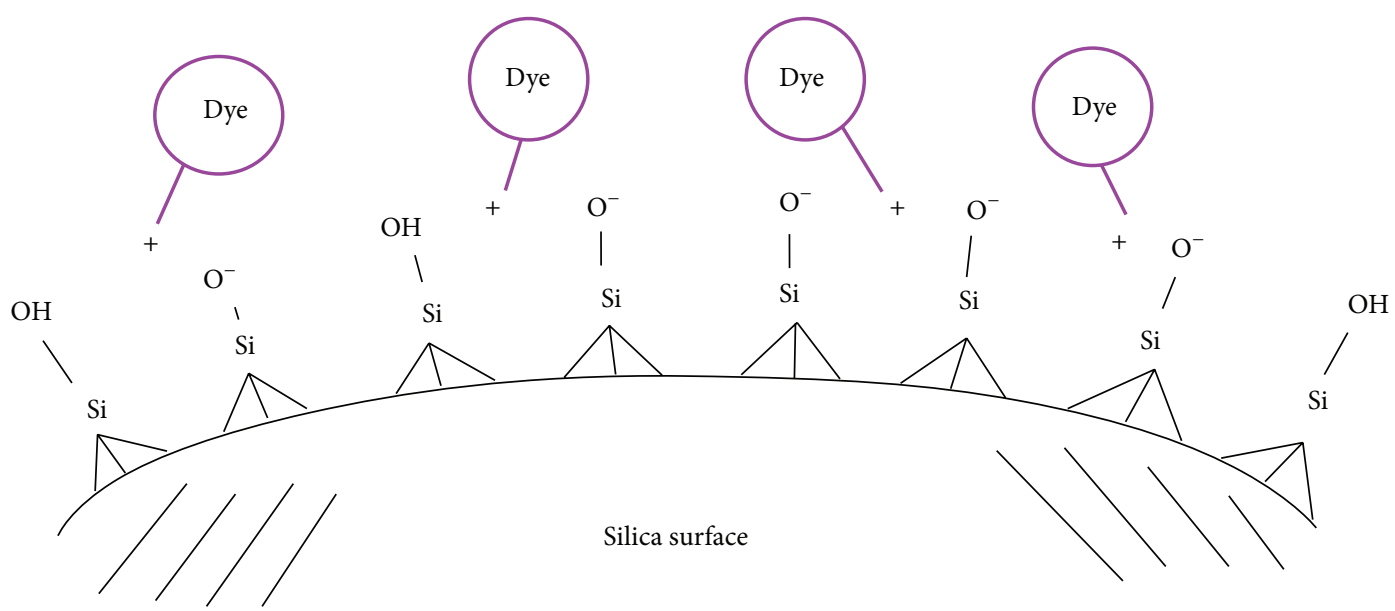

FIGURE 2: Electrostatic interaction of $\mathrm{CV}$ and sorbent.

that can be attained as $C_{e}$ increases. The $b$ parameter is a coefficient related to the energy of adsorption and increases with increasing the strength of the adsorption bond and $q_{\max }$ is the monolayer capacity of the sorbent $\left(\mathrm{mg} \mathrm{g}^{-1}\right)$. Values of $q_{\max }$ and $b$ are determined from the linear regression plot of $\left(C_{e} / q_{e}\right)$ versus $C_{e}$. The Freundlich [16] equation is expressed in its linearized form as follows:

$$
\ln q_{e}=\ln K_{F}+\frac{1}{n} C_{e},
$$

where $K_{F}$ and $n$ are the constants of the Freundlich equation representing the capacity of the adsorbent for the adsorbate and the reaction order, respectively. The reciprocal reaction order, $1 / n$, is a function of the strength of adsorption. The value of $1 / n \geq 1$ which is obtained from Freundlich model indicates that saturation was not attained. So, according to the results, in this system saturation was attained and also the adsorbent surface did not have heterogeneity.

\section{Results and Discussion}

The XRD pattern recorded in Figure 3 displays three peaks at $2 \theta=2.75^{\circ}, 4.72^{\circ}$ and $5.30^{\circ}$, which are typical (100), (110), and (200) associated with the of one-dimensional hexagonal symmetry of mesostructures [17]. This indicates that ordered SBA- 3 has been prepared according to the procedure described.

The nitrogen adsorption isotherm is recorded in Figure 4. Its general feature appears to be a type IV isotherm. The adsorption step between 0.20 and $0.30 P / P_{0}$ is due to the capillary condensation in the mesopores of SBA-3. Further, its initial part shows a high "knee" (e.g., the adsorbed volume of liquid $\mathrm{N}_{2}$ reaches $0.20 \mathrm{~cm}^{3} \mathrm{~g}^{-1}$ at $0.001 P / P_{0}$ ). This implies the presence of micropores in SBA-3 [18]. In combination with both observations, the isotherm Figure 3 represents a superposition of type I and type IV isotherms, as stated in the literature [19]. The BET surface area and pore volume are $1420 \mathrm{~m}^{2} \mathrm{~g}^{-1}$ and $0.91 \mathrm{~cm}^{3} \mathrm{~g}^{-1}$, respectively.

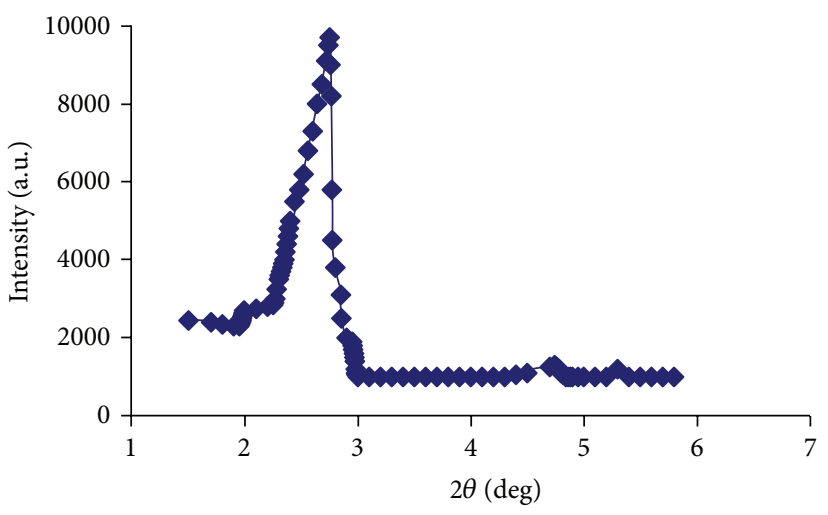

FiguRE 3: XRD patterns of SBA-3.

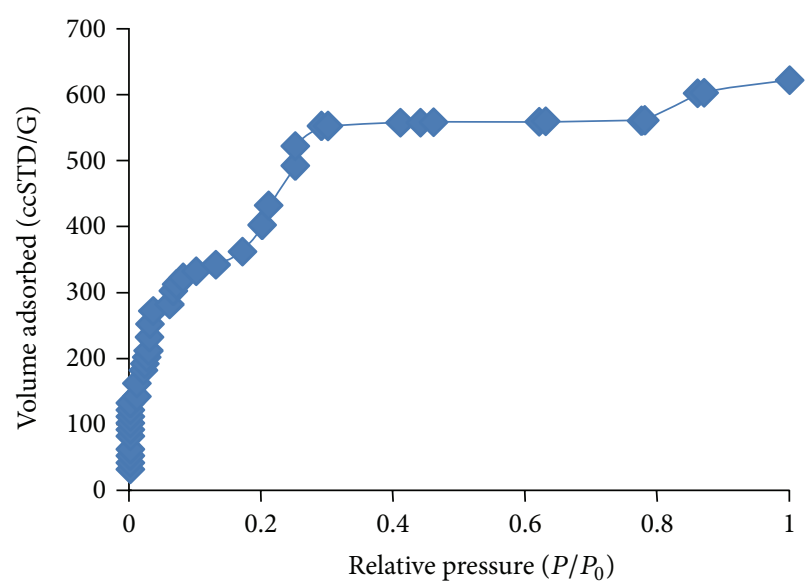

FIgURE 4: Adsorption desorption isotherm of nitrogen at $77 \mathrm{~K}$ on SBA-3.

Scanning electron microscopy images of SBA-3 sample are shown in Figure 5. The figure shows the size and shape of the crystals. 

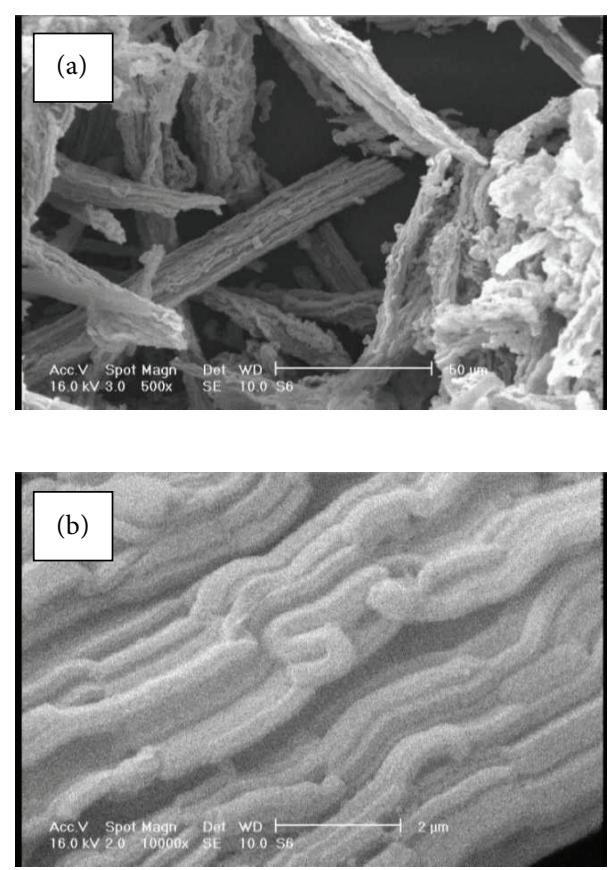

FIGURE 5: SEM microphotographs of SBA-3 (a) $50 \mu \mathrm{m}$ and (b) $2 \mu \mathrm{m}$.

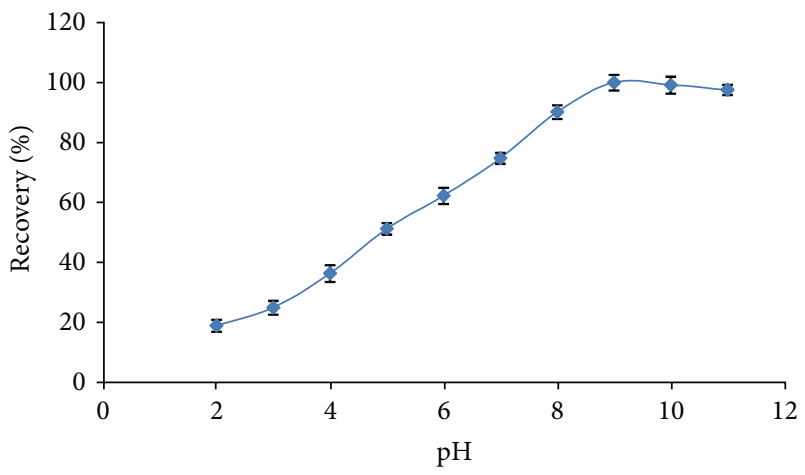

FIGURE 6: Effect of $\mathrm{pH}$ on the recovery of CV. Conditions: amount of CV: $50 \mu \mathrm{g} \mathrm{L}^{-1}$, sample volumes $25 \mathrm{~mL}$, amount of sorbent: $15 \mathrm{mg}$, eluent: glacial acetic acid, and eluent volume: $1.0 \mathrm{~mL}$.

3.1. Effect of $p H$. Identification of the optimum $\mathrm{pH}$ is very important because it affects the structural properties of sorbent and analytes. The effect of $\mathrm{pH}$ on the recovery of crystal violet was studied with $\mathrm{pH}$ varying from 2 to 11 . It was found that the extraction recovery of the dye was insignificant at $\mathrm{pH} 3$ and increased in $\mathrm{pH}$ range between 3 and 9 (Figure 6).

The effect of $\mathrm{pH}$ can be explained in terms of electrostatic interactions initiated by the adsorbent. At lower $\mathrm{pH}$, lower recoveries were due to the presence of excess $\mathrm{H}^{+}$ions competing with the dye cations for adsorption sites. As the $\mathrm{pH}$ becomes less acidic (higher $\mathrm{pH}$ ), the surface of SBA-3 particles may become negatively charged, which enhances the positively charged CV cations through electrostatic forces of attraction.

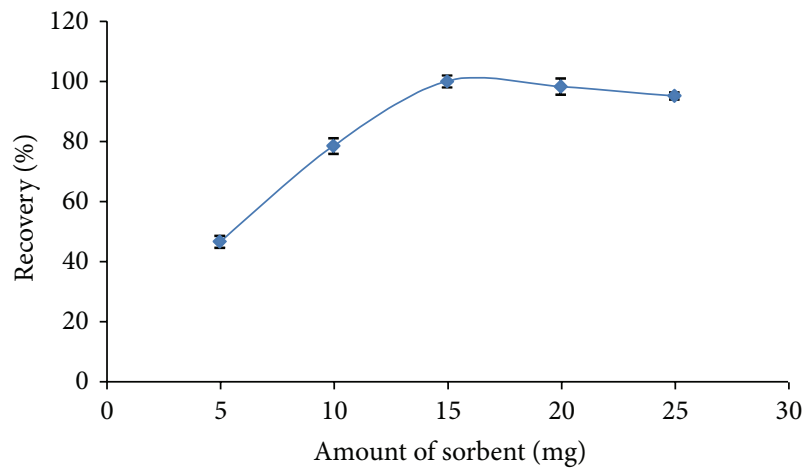

Figure 7: Effect of amount of sorbent on the recovery of CV. Conditions: $\mathrm{pH}$ : 9, amount of CV: $50 \mu \mathrm{g} \mathrm{L}^{-1}$, sample volume: $25 \mathrm{~mL}$, eluent: glacial acetic acid, and eluent volume: $1.0 \mathrm{~mL}$.

3.2. Effect of the Adsorbent Amounts. In order to estimate the optimum adsorbent quantity, the recovery of crystal violet was examined by using the adsorbent quantities in the range of 5-25 mg. The results shown in Figure 7 indicate that the quantitative recovery ( $>95 \%$ ) of crystal violet was obtained by increasing of mesoporous silica SBA-3 amount up to $15 \mathrm{mg}$.

3.3. Extraction Time. The extraction recovery was studied at time intervals in the range of $0.5-10 \mathrm{~min}$. As shown in Figure 8 when the sample solution was shaken only for $2 \mathrm{~min}$, the extraction recoveries of the dye reached its maximum. Thus, the mixtures have been shaken for $2 \mathrm{~min}$ to reach equilibrium in the subsequent experiments. 


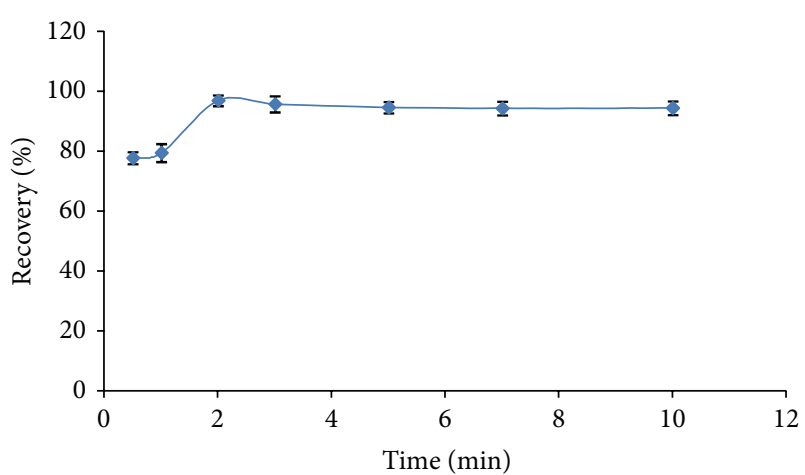

Figure 8: Effect of extraction time on the recovery of CV. Conditions: $\mathrm{pH}$ : 9, amount of $\mathrm{CV}: 50 \mu \mathrm{g} \mathrm{L}{ }^{-1}$, sample volume: $25 \mathrm{~mL}$, amount of sorbent: $15 \mathrm{mg}$, and eluent: glacial acetic acid.

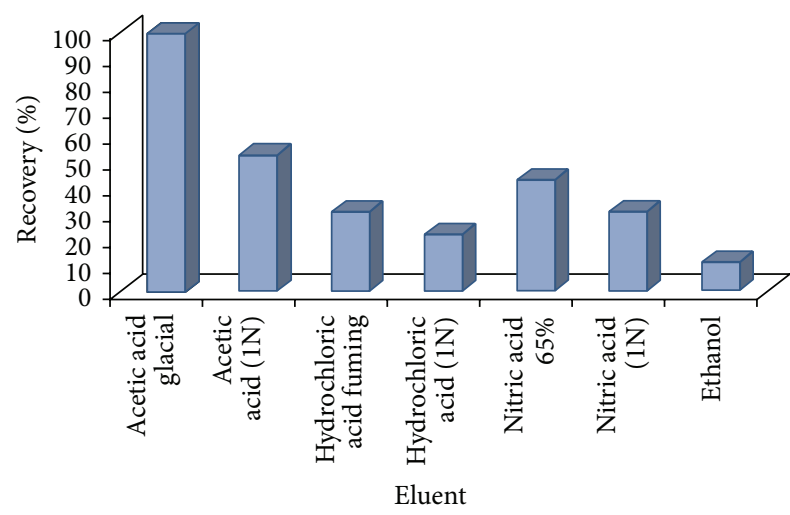

FIGURE 9: Effects of various eluents on the recoveries of CV (eluent volume: $1 \mathrm{~mL}$ ).

3.4. Desorption Conditions. In a SPE procedure, eluent and its volume are an important parameter. It is obvious from Figure 9 that the adsorptions of crystal violet decrease sharply with the decrease of $\mathrm{pH}$ value. For this reason, various concentrations of various acids were studied for desorption of the retained dye from the sorbent. The resulting data as shown in Figure 8 indicate that the quantitative recovery for crystal violet was obtained by using glacial acetic acid.

The effect of the volume of eluent solution was also studied (Figure 10). The recovery percentage of the dye increased by increasing the volume of glacial acetic acid up to $1.0 \mathrm{~mL}$ and remained constant afterward. Therefore, optimum volume of the eluent was chosen as $1.0 \mathrm{~mL}$. Desorption times were evaluated in the range of $0.5-5 \mathrm{~min}$. The results showed that the time of $1 \mathrm{~min}$ is sufficient to quantitative desorption of the dye.

3.5. Effect of Sample Volume. Sample volume is one of the important parameters for obtaining high preconcentration factor. For that reason, the maximum sample volume was optimized by the investigation of the recovery of crystal violet in various synthetic samples and volumes in the range of 25 $250 \mathrm{~mL}$ containing $1.25 \mu \mathrm{g}$ of crystal violet were used to study (Figure 11). The recovery of crystal violet was quantitative

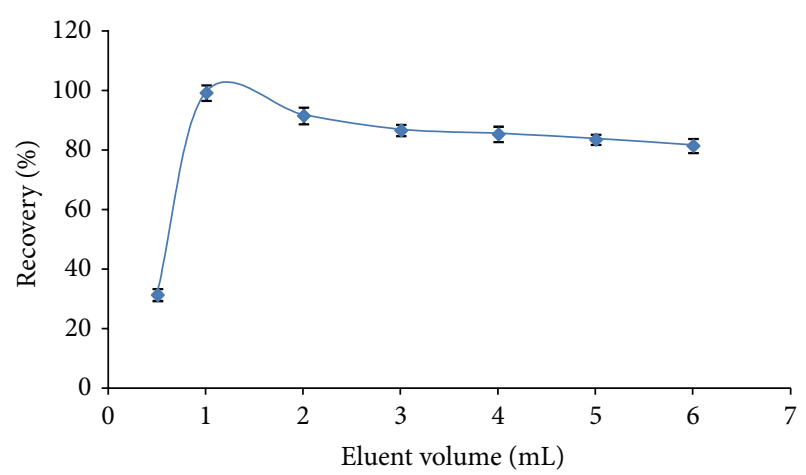

Figure 10: Effect of eluent volume on the recovery of CV. Conditions: pH: 9, amount of CV: $50 \mu \mathrm{gL}^{-1}$, sample volume: $25 \mathrm{~mL}$, amount of sorbent: $15 \mathrm{mg}$, eluent: glacial acetic acid, and extraction time: $2 \mathrm{~min}$.

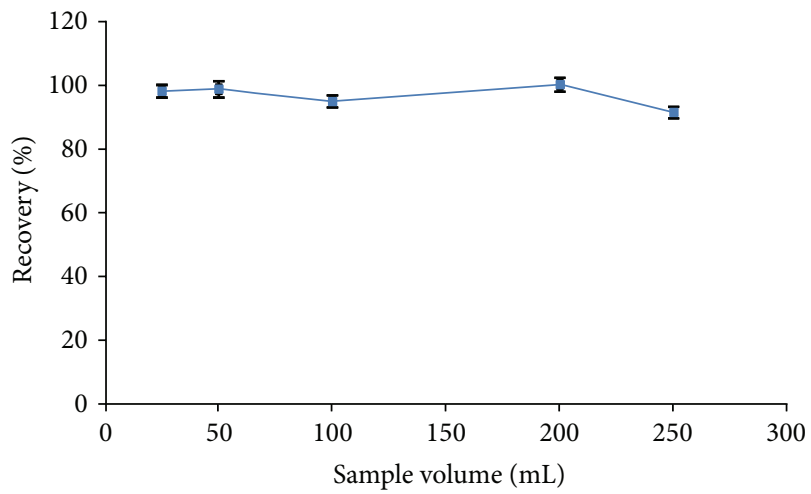

FIGURE 11: Effect of sample volume on the recovery of CV. Conditions: $\mathrm{pH}$ : 9, amount of CV: $1.25 \mu \mathrm{g} \mathrm{CV}$, amount of sorbent: $15 \mathrm{mg}$, eluent: glacial acetic acid, eluent volume: $1.0 \mathrm{~mL}$, and extraction time: $2 \mathrm{~min}$.

(>95\%) for sample volumes up to $200 \mathrm{~mL}$, thus enabling the preconcentration factor of 200 for CV.

3.6. Adsorption Isotherms and Maximum Capacity of the Sorbent. The adsorption isotherm is important from both a theoretical and practical point of view. The adsorption isotherm of a specific adsorbent represents its adsorptive characteristics which is very important for designing the adsorption processes. Adsorption isotherms were obtained by shaking $15 \mathrm{mg}$ of SBA-3 in $25 \mathrm{~mL}$ of the CV solutions (concentrations ranging from 50 to $550 \mathrm{mg} \mathrm{L}^{-1}$ ) under the optimum conditions (Figure 12). The linearized form of the Langmuir (2) and Freundlich (3) adsorption isotherms were used to evaluate the relationship between the concentration of adsorbed CV by SBA- 3 and CV equilibrium concentration in aqueous solution. The obtained correlation coefficients $\left(R_{\text {Langmuir }}=0.992\right.$ and $\left.R_{\text {Freundlich }}=0.976\right)$ showed that CV adsorption equilibrium data were fitted well to the Langmuir isotherm (Figure 12(a)) rather than Freundlich (Figure 12(b)) isotherm. The maximum monolayer capacity $\left(q_{\max }\right)$ and the Langmuir constant $(b)$ as calculated from the Langmuir model were $344.83 \mathrm{mgg}^{-1}$ and $0.332 \mathrm{~L} \mathrm{mg}^{-1}$, 


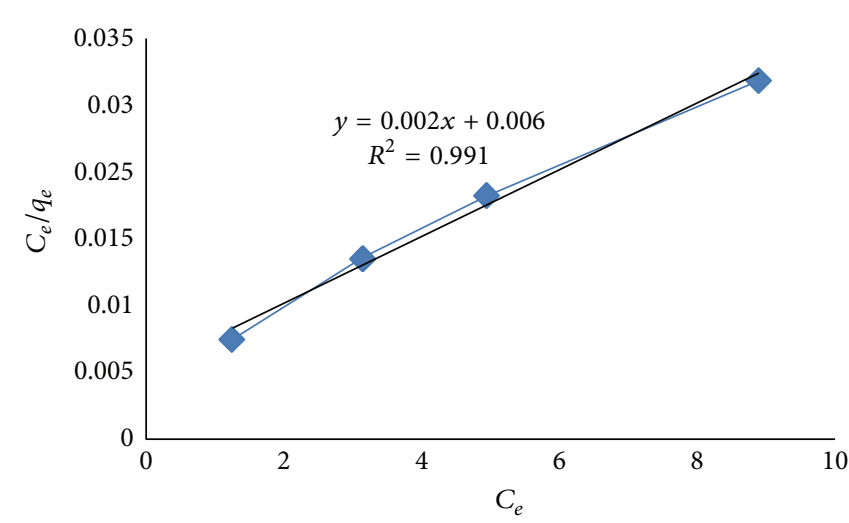

(a)

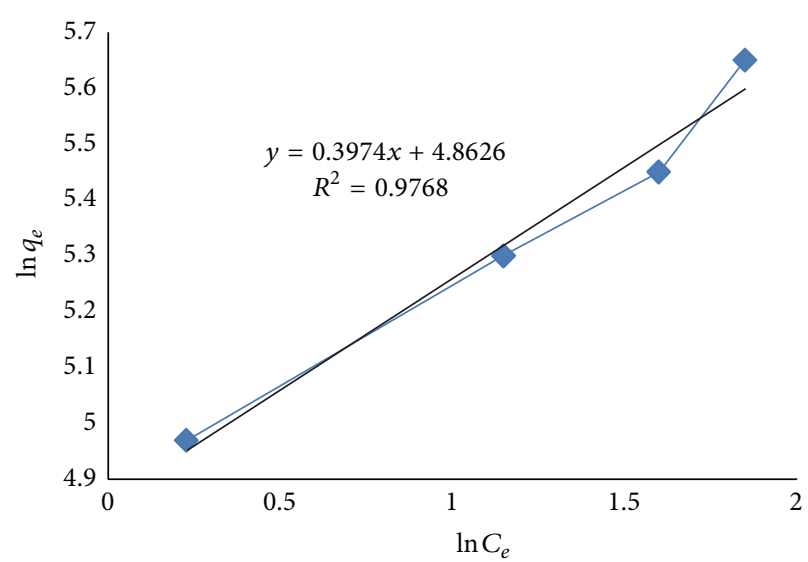

(b)

FIGURE 12: (a) Langmuir isotherm plots; (b) Freundlich isotherm plots for CV adsorption onto SBA-3 nanosorbent. Experimental conditions: sample solution, $25 \mathrm{~mL}$; solution $\mathrm{pH}$, 9; amount of adsorbent, $15 \mathrm{mg}$; contact time, $2 \mathrm{~min}$ and initial CV concentration of 50-550 mg $\mathrm{L}^{-1}$.

TABLE 1: Adsorption isotherms' parameters of CV.

\begin{tabular}{lccccc}
\hline & \multicolumn{3}{c}{ Freundlich model } & \multicolumn{2}{c}{ Langmuir model } \\
\hline Analyte & $K_{F}(\mathrm{mg} / \mathrm{g})$ & $n(\mathrm{~L} / \mathrm{mg})$ & $R^{2}$ & $q_{m}(\mathrm{mg} / \mathrm{g})$ & $b(\mathrm{~L} / \mathrm{mg})$ \\
Crystal violet & 129.28 & 2.51 & 0.976 & 344.83 & 0.332 \\
\hline
\end{tabular}

respectively. Table 1 summarizes the models' constants and the determination coefficients.

3.7. Stability and Reusability of SBA-3. To test the reusability and regeneration of the sorbent, it was used in consecutive adsorption/desorption cycles in accordance with the extraction procedure. In this experiment, solutions containing crystal violet $\left(50 \mu \mathrm{g} \mathrm{L}^{-1}\right)$ were added to a tube containing $15 \mathrm{mg}$ of SBA-3 and the stability and regeneration potential of the sorbent were evaluated by observing the changes in the recoveries of crystal violet. After each cycle of adsorption/desorption, the sorbent was washed thoroughly with doubly distilled water and then reconditioned for adsorption in the succeeding cycle. It was found that the sorbent was able to quantitatively extract $\mathrm{CV}$ in more than 46 cycles.

3.8. Analytical Figures of Merit. The result of calibration curve shows that it is linear up to $200 \mu \mathrm{g} \mathrm{L}^{-1}$. The correlation coefficient was 0.992 . The limit of detection LOD was calculated as $3 S_{b} / m$, where $m$ is the slope of the calibration curve and $S_{b}$ is the standard deviation of five consecutive measurements of the blank solution. The LOD value was $1.3 \mu \mathrm{g} \mathrm{L}^{-1}$. The relative standard deviation of five replicates was found to be less than $1.3 \%$ at $50 \mu \mathrm{g} \mathrm{L}^{-1}$ of $\mathrm{CV}$. As the amount of crystal violet in the sample solution was measured after a final volume of nearly $1 \mathrm{~mL}$, the solution was concentrated by a factor of 200 and in this method target analyte adsorbed to sorbent only in $2 \mathrm{~min}$ so; this method is very fast.
3.9. Analysis of Water Samples. The application and validation of the proposed method was verified by subjecting SBA-3 to fish, fish farming water, and river water samples, under optimal experimental conditions. Before the analysis, the samples were filtered through a $0.45 \mu \mathrm{m}$ membrane filter. The results are given in Table 2 . The method was validated after spiking different amounts of $\mathrm{CV}$ to the samples. A good agreement was obtained between the added and measured $\mathrm{CV}$ amounts. The recovery values calculated from the spiked standards were higher than $95 \%$ for all the cases. These results showed that the proposed solid phase extraction procedure could be applied for analysis of these samples satisfactorily.

3.10. Comparison of Analytical Performance Data with the Literature. A comparison of the represented SPE method with other reported preconcentration methods is given in Table 3. In comparison with other reported methods, the proposed method has low LOD $\left(1.3 \mu \mathrm{gL}^{-1}\right)$, high preconcentration factor (200), and very fast extraction time (only $2 \mathrm{~min}$ ). All these results indicate that SPE combined with FOLADS is a very simple, fast, and sensitive method for the preconcentration and determination of dyes like CV from water samples.

\section{Conclusions}

This work proved that SBA-3 nanosorbent can act as an effective solid phase for the sorption of crystal violet (CV). This may be due to the electrostatic interactions among 
TABLE 2: Determination of crystal violet in different samples.

\begin{tabular}{|c|c|c|c|c|}
\hline Sample & $\mathrm{CV}$ added $\left(\mu \mathrm{gL}^{-1}\right)$ & $\mathrm{CV}$ found $\left(\mu \mathrm{gL}^{-1}\right)$ & $\mathrm{RSD}^{\mathrm{a}}(\%)$ & Recovery (\%) \\
\hline Fish (salmon) & - & 1.6 & 1.1 & - \\
\hline Fish (salmon) & 50 & 51.5 & 1.2 & 99.8 \\
\hline Fish (salmon) & 70 & 71.9 & 1.5 & 100.4 \\
\hline Fish farming water ${ }^{b}$ & - & $\mathrm{BDL}^{\mathrm{d}}$ & - & - \\
\hline Fish farming water & 50 & 49.7 & 1.2 & 99.4 \\
\hline Fish farming water & 70 & 70.2 & 1.6 & 100.2 \\
\hline River water ${ }^{c}$ & - & $\mathrm{BDL}$ & - & - \\
\hline River water & 50 & 48.3 & 1.4 & 96.6 \\
\hline River water & 70 & 70.1 & 1.7 & 100.1 \\
\hline
\end{tabular}

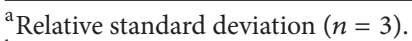

${ }^{\mathrm{b}}$ Collected from trout fish farming pools, Amol, Iran.

${ }^{\mathrm{c}}$ Collected from river, Hamedan, Iran.

${ }^{\mathrm{d}}$ Below Detection Limit.

TABLE 3: A comparison of the represented SPE method with other reported preconcentration methods.

\begin{tabular}{|c|c|c|c|c|c|}
\hline Method & Time (min) & $\mathrm{PF}^{\mathrm{a}}$ & $\operatorname{LOD}\left(\mu \mathrm{gL}^{-1}\right)$ & Linearly range $\left(\mu \mathrm{gL}^{-1}\right)$ & Reference \\
\hline CPE-Spectrophotometry $^{\mathrm{b}}$ & 20 & - & 4.8 & $16-1000$ & [5] \\
\hline SPE-Spectrophotometry ${ }^{c}$ & - & $89-96$ & 28 & $120-8000$ & [6] \\
\hline RDSE-direct solid phase Spectrophotometry ${ }^{\mathrm{d}}$ & 100 & - & 1.8 & $5-225$ & [7] \\
\hline$S P E^{e}-F O-L A D S^{f}$ & 2 & 200 & 1.3 & $4-200$ & This work \\
\hline
\end{tabular}

${ }^{\text {a }}$ Preconcentration factor

${ }^{\mathrm{b}}$ Cloud point extraction.

${ }^{\mathrm{c}}$ Diatomite.

${ }^{d}$ Rotating disk sorptive extraction.

${ }^{\mathrm{e}}$ Nanoporous silica SBA-3.

${ }^{\mathrm{f}}$ Fiber optic-linear array detection spectrophotometry.

negatively charged SBA-3 and the positively charged dye. Two of the most important characteristics of the synthesized SBA3 nano sorbent are the fast sorption and desorption of crystal violet dye. Due to a relatively high preconcentration factor (200), trace amounts of CV at $\mu \mathrm{g} \mathrm{L}^{-1}$ levels can be determined accurately. Comparison of analytical features of this method with those of some other preconcentration techniques in Table 3 indicates that the linear range, LOD, preconcentration factor, and extraction time of this method are better than or comparable with most of the other methods. The Langmuir and Freundlich adsorption isotherm models were applied to the adsorption data of $\mathrm{CV}$ onto SBA- 3 at $25^{\circ} \mathrm{C}$. The Langmuir isotherm was the best model to describe the experimental data. The results obtained from the analysis of fish, fish farming water, and river water samples prove the reliability of the proposed method.

\section{Acknowledgment}

Support of this investigation by the Research Council of University of Tehran through a grant is gratefully acknowledged.

\section{References}

[1] O. J. Hao, H. Kim, and P.-C. Chiang, "Decolorization of wastewater," Critical Reviews in Environmental Science and Technology, vol. 30, no. 4, pp. 449-505, 2000.
[2] S. Li, "Removal of crystal violet from aqueous solution by sorption into semi-interpenetrated networks hydrogels constituted of poly(acrylic acid-acrylamide-methacrylate) and amylose," Bioresource Technology, vol. 101, no. 7, pp. 2197-2202, 2010.

[3] W. Au, S. Pathak, C. J. Collie, and T. C. Hsu, "Cytogenetic toxicity of gentian violet and crystal violet on mammalian cells in vitro," Mutation Research, vol. 58, no. 2-3, pp. 269-276, 1978.

[4] C.-C. Chen, H.-J. Liao, C.-Y. Cheng, C.-Y. Yen, and Y.-C. Chung, "Biodegradation of crystal violet by Pseudomonas putida," Biotechnology Letters, vol. 29, no. 3, pp. 391-396, 2007.

[5] L. An, J. Deng, L. Zhou et al., "Simultaneous spectrophotometric determination of trace amount of malachite green and crystal violet in water after cloud point extraction using partial least squares regression," Journal of Hazardous Materials, vol. 175, no. 1-3, pp. 883-888, 2010.

[6] Y. S. Al-Degs and J. A. Sweileh, "Simultaneous determination of five commercial cationic dyes in stream waters using diatomite solid-phase extractant and multivariate calibration," Arabian Journal of Chemistry, vol. 5, no. 2, pp. 219-224, 2012.

[7] V. Manzo, O. Navarro, L. Honda, K. Sánchez, M. I. Toral, and P. Richter, "Determination of crystal violet in water by direct solid phase spectrophotometry after rotating disk sorptive extraction," Talanta, vol. 106, pp. 305-308, 2013.

[8] J. S. Suleiman, B. Hu, H. Peng, and C. Huang, "Separation/ preconcentration of trace amounts of $\mathrm{Cr}, \mathrm{Cu}$ and $\mathrm{Pb}$ in environmental samples by magnetic solid-phase extraction with Bismuthiol-II-immobilized magnetic nanoparticles and their determination by ICP-OES," Talanta, vol. 77, no. 5, pp. 15791583, 2009. 
[9] M. Tian, H. Yan, and K. H. Row, "Solid-phase extraction of tanshinones from Salvia Miltiorrhiza Bunge using ionic liquidmodified silica sorbents," Journal of Chromatography B, vol. 877, no. 8-9, pp. 738-742, 2009.

[10] C. T. Kresge, M. E. Leonowicz, W. J. Roth, J. C. Vartuli, and J. S. Beck, "Ordered mesoporous molecular sieves synthesized by a liquid-crystal template mechanism," Nature, vol. 359, no. 6397, pp. 710-712, 1992.

[11] M. Al-Harahsheh, R. Shawabkeh, A. Al-Harahsheh, K. Tarawneh, and M. M. Batiha, "Surface modification and characterization of Jordanian kaolinite: application for lead removal from aqueous solutions," Applied Surface Science, vol. 255, no. 18, pp. 8098-8103, 2009.

[12] M. Anbia and S. E. Moradi, "Adsorption of naphthalene-derived compounds from water by chemically oxidized nanoporous carbon," Chemical Engineering Journal, vol. 148, no. 2-3, pp. 452458, 2009.

[13] M. Anbia and M. Lashgari, "Synthesis of amino-modified ordered mesoporous silica as a new nano sorbent for the removal of chlorophenols from aqueous media," Chemical Engineering Journal, vol. 150, no. 2-3, pp. 555-560, 2009.

[14] Q. Huo, D. I. Margolese, and G. D. Stucky, "Surfactant control of phases in the synthesis of mesoporous silica-based materials," Chemistry of Materials, vol. 8, no. 5, pp. 1147-1160, 1996.

[15] I. Langmuir, "The constitution and fundamental properties of solids and liquids. Part I. Solids," Journal of the American Chemical Society, vol. 38, no. 2, pp. 2221-2295, 1916.

[16] H. M. F. Freundlich, "Over the adsorption in solution," The Journal of Chemical Physics, vol. 57, pp. 385-470, 1906.

[17] F. Chen, X.-J. Xu, S. Shen, S. Kawi, and K. Hidajat, "Microporosity of SBA-3 mesoporous molecular sieves," Microporous and Mesoporous Materials, vol. 75, no. 3, pp. 231-235, 2004.

[18] K. R. Ramakrishna and T. Viraraghavan, "Use of slag for dye removal," Waste Management, vol. 17, no. 8, pp. 483-488, 1998.

[19] M. S. El-Geundi, "Homogeneous surface diffusion model for the adsorption of basic dyestuffs onto natural clay in batch adsorbers," Adsorption Science and Technology, vol. 8, no. 4, pp. 217-225, 1991. 

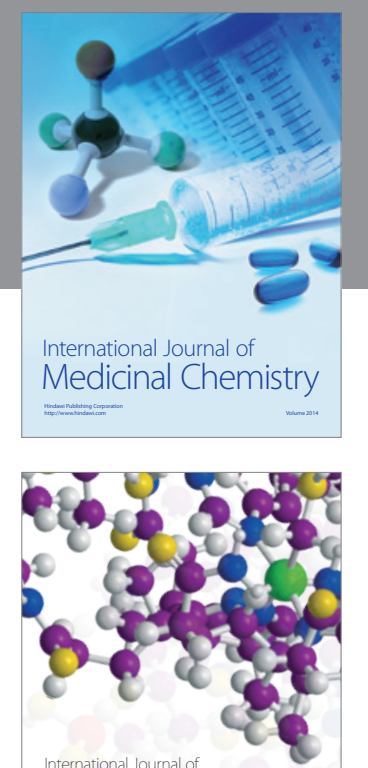

\section{Carbohydrate} Chemistry

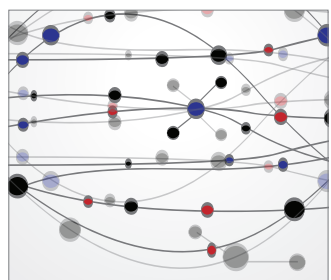

The Scientific World Journal
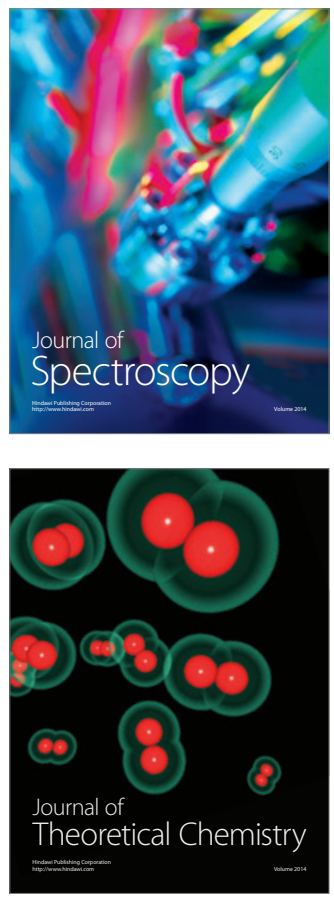
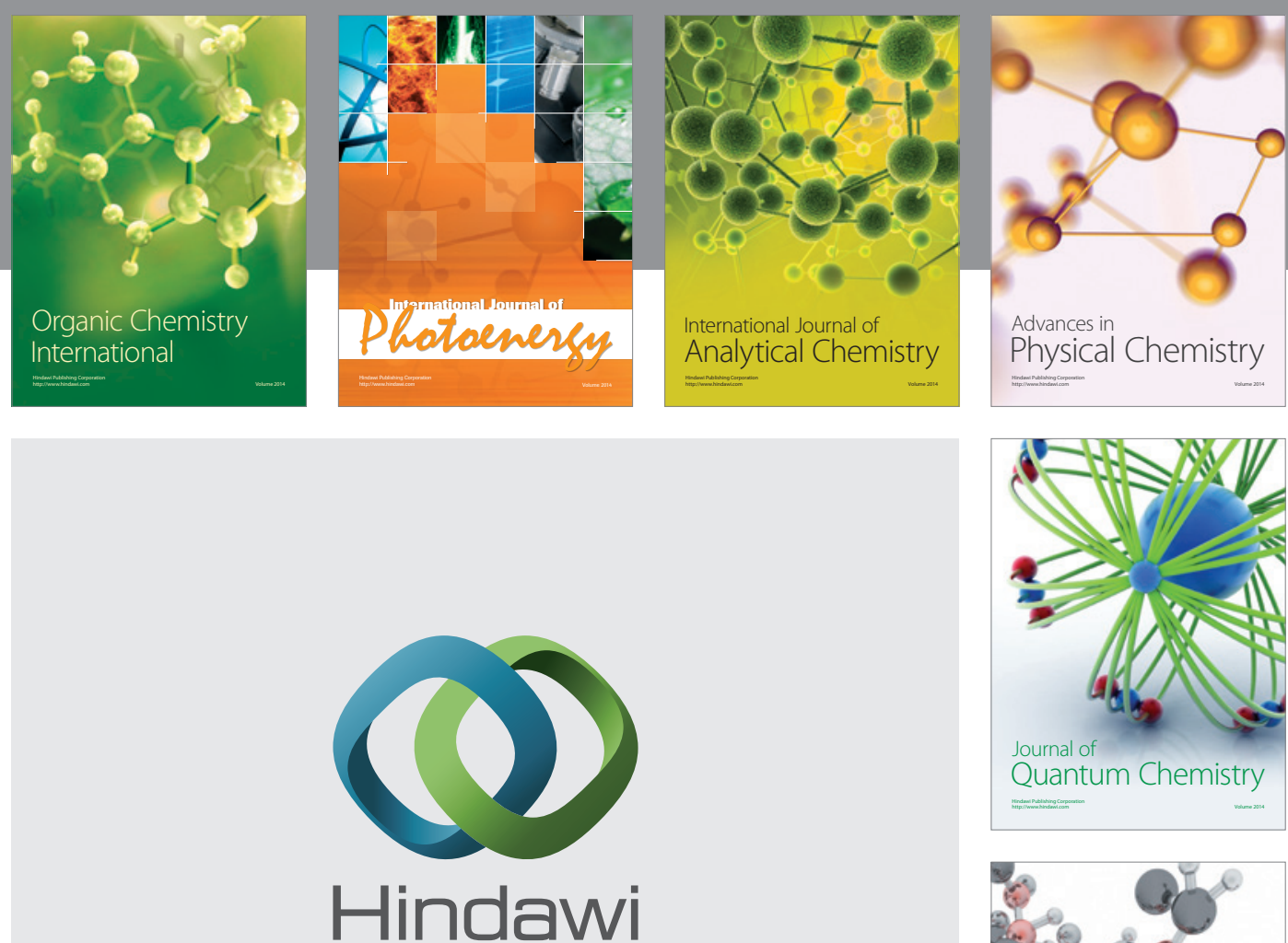

Submit your manuscripts at

http://www.hindawi.com

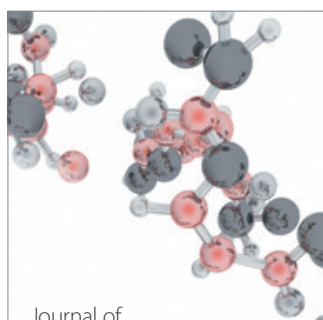

Analytical Methods

in Chemistry

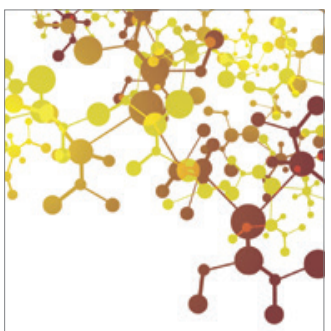

Journal of

Applied Chemistry

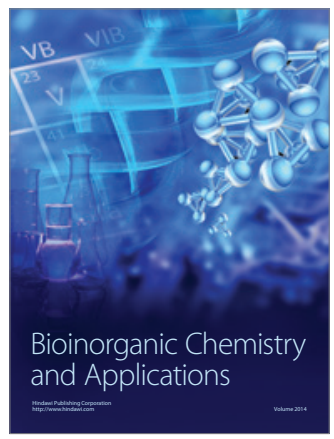

Inorganic Chemistry
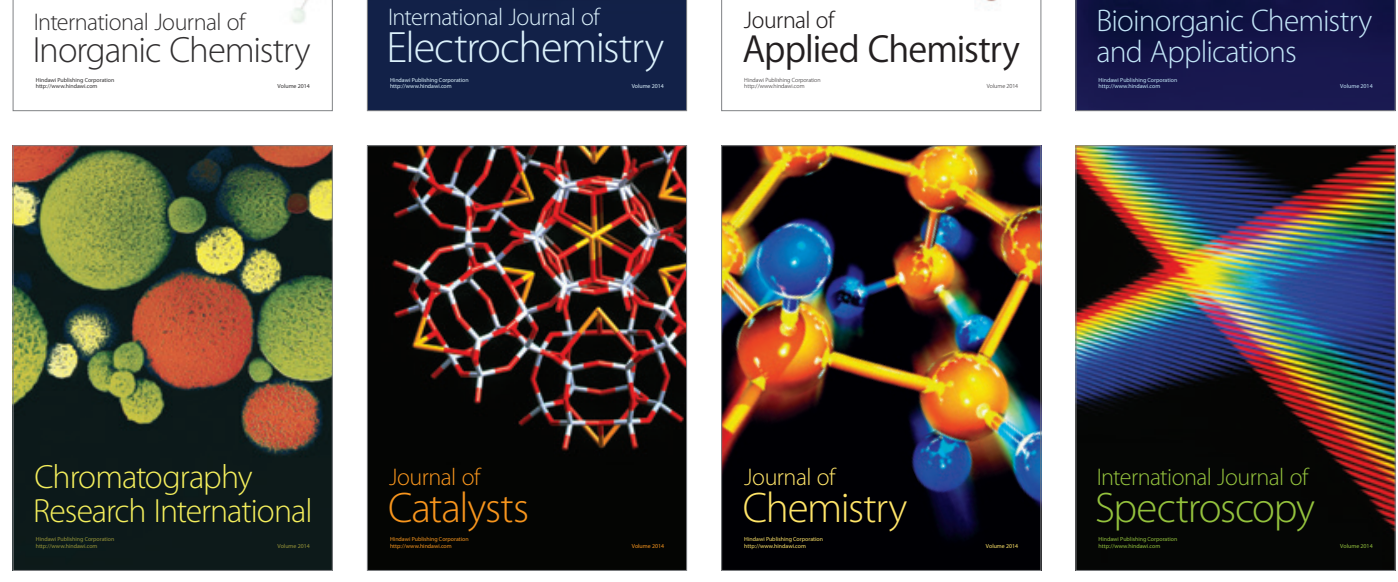